\title{
Attitudes of University Students towards People with Disabilities in the Social Context: A Preliminary Study
}

\author{
Azzahrah Anuar ${ }^{*}$ \\ Nor Mazlina Ghazali² \\ 1,2Universiti Malaysia Sarawak, 94300 Kota Samarahan, Sarawak, Malaysia
}

\begin{abstract}
The article highlights on the previous literature on the attitudes of college or university students towards people with disabilities in the social context globally. The article also includes factors that influence the willingness of college or university students to build relationship with people with disabilities in the social context (such as friendship, dating, and marriage) and perceptions of students that add to the existing challenges encountered by people with disabilities. When perception is being measured in a more specific dimension, such as, in the social distance context, it provides a practical means to understand people's awareness towards disability.
\end{abstract}

Keywords: university student attitude; people with disabilities; social context

\section{INTRODUCTION}

The motivation for studying attitudes towards people with disabilities stems from the identification of negative attitudes and their apparent connection to bias and discrimination. Negative attitudes are thought to be at least partially responsible for discrimination encountered by people with disabilities in many social facets of life (Rubin \& Roessler, 2008). Such attitudes create barriers to developing a positive social engagement with people with disabilities.

\section{ARTICLE INFO}

E-mail address:

aazzahrah@unimas.my (Azzahrah Anuar)

*Corresponding author

ISSN: $2462-1153$

(C) Faculty of Cognitive Sciences and Human Development, Universiti Malaysia Sarawak (UNIMAS)
The attitudes held towards people with disabilities vary. A large body of research has documented societal attitudes towards people with disabilities in general. However, little research has been done to explore attitudes towards people with disabilities in a more specific context, such as, engaging in personal relationships or building friendships. Many studies related to this area have taken place in the Western culture, particularly, in the United States. Little research has been published and is 
Azzahrah Anuar and Nor Mazlina Ghazali

known about the generalizability of the attitudinal patterns to other cultures (Chen, Brodwin, Cardosa, \& Chan, 2002).

\section{SOCIAL DISTANCE ATTITUDES}

Social distance is an essential component in measuring attitudes. To measure social distance, individuals will be expected to indicate their willingness to interact with people with disabilities in different social situations (Wahl \& Aroesty-Cohen, 2010). There has been suggestions on the measurement of attitudes towards people with disabilities should account for disabilityspecific and social situation-specific factors (Strohmer, Grand, \& Purcell, 1984).

Marginalized group, such as, people with disabilities are viewed at a social distance due to stigma developed by other people (Hergenrather \& Rhodes, 2007). Persons without disabilities perceive those with disabilities to be different across several social dimensions, such as, being more socially anxious, uncomfortable about dating, and reluctant to develop relationship with others (Fichten, Robillard, Judd, \& Amsel, 1989). Individuals who found they have more similarities with people with disabilities may have desired less social distance than those who perceived people with disabilities as far more different than them (Miller, Chen, Glover-Graf, \& Kranz, 2009). Increased social distance can lead to inequity for people with disabilities because of individuals' prejudicial attitudes and attitudinal barriers that prevent people with disabilities from becoming active participants in the community.

The reactions towards people with disabilities in the social context vary in the literature. Antonak (1981) and Grand, Bernier, and Strohmer (1982) found that interactions between people with disabilities and people without disabilities often result in shorter conversations, less physi- cal contact, and less personal and meaningful conversations (as cited in Miller et al., 2009, p. 211). Negative attitudes were particularly more apparent in the context of dating and marriage. Previous studies have shown that as the relationship deepens, the attitudes toward having relationships with people with disabilities become increasingly negative (Gill, 1996; Olkin, 1999). These negative attitudes may stem in part from the anticipation of stigma by association. Several studies have found that participants expressed their concerns about being stigmatized by others when they dated or married someone with a disability (Asch \& Fine, 1988; Fitches, Goodrick, Amsel, \& McKenzies, 1991; Siller, 1964; Gordon, Minnes, \& Holden, 1990). As an example, in other research that investigated the perceptions of college students on dating partners of persons with physical disabilities, the partners of persons with physical disabilities were perceived as being significantly different than partners of persons without disabilities. Even though they were rated as being trustworthy and nurturing, they were also viewed as being less intelligent, sociable, and athletic than people without disabilities (Goldstein \& Johnson, 1997).

Most of the studies have found that attitudes towards dating and marrying people with disabilities have been evaluated less favorably than attitudes in the social context of work (Deloach, 1994; Grand et al., 1982; Karnilowicz, Sparrow, \& Shinkfield, 1994; Strohmer, Grand, \& Purcell, 1984; Stovall \& Sedlacek, 1983; Gordon et al., 1990). In Gordon et al. study, the highest mean acceptance score was found on the Work scale, consistent with the results of Grand et al. (1982) and Strohmer et al. (1984). Miller et al. (2009) conducted a study at a southwestern Hispanic-serving public university and reported students were most willing to have friendships and 
somewhat less willing to have dating relationships. Students were also reported to be least willing to marry a person with a disability in their study.

RESEARCH ON ATTITUDES TOWARDS PEOPLE WITH DISABILITIES IN THE SOCIAL CONTEXT SUMMARY

Studies have shown that attitudes vary based on gender, the extent of the relationships with people with disabilities, cultural factor, the characteristics of persons with disabilities, and other variables. Some of the literature have indicated that women have more favorable attitudes than men toward people with disabilities even though there was no absolute explanation that contributed to such results. On the other hand, the attitudes of males and females in the social context are more com-

Table 1: Studies on Attitudes towards People with Disabilities in the Social Context by Gender Factor

\begin{tabular}{|l|l|}
\hline \multicolumn{1}{|c|}{ Study } & \multicolumn{1}{c|}{ Findings } \\
\hline Chen et al. (2002) & $\begin{array}{l}\text { American female students had more positive attitudes about } \\
\text { dating and marrying people with disabilities compared } \\
\text { to the American male students, both male and female } \\
\text { Taiwanese and Singaporean students. }\end{array}$ \\
\hline $\begin{array}{l}\text { Hergenrather and } \\
\text { Rhodes (2007) }\end{array}$ & $\begin{array}{l}\text { Women were more comfortable than men when interacting } \\
\text { with people with disabilities in the domains of dating, } \\
\text { marriage, and work. However, the attitudes appear to } \\
\text { become more negative as the social context becomes more } \\
\text { intimate. }\end{array}$ \\
\hline Miller et al. (2009) & $\begin{array}{l}\text { Women are considerably less willing to have a relationship } \\
\text { especially in the context of dating and marriage although } \\
\text { women are more likely to have friendships with people } \\
\text { with disabilities. }\end{array}$ \\
\hline Hamdy et al. (2011) & $\begin{array}{l}\text { American and Egyptian male college students were more } \\
\text { positive about people with disabilities than were women } \\
\text { in overall. Hamdy et al. added that the Egyptian male } \\
\text { students generally have a more positive attitude than } \\
\text { the Egyptian female students with the highest scores on } \\
\text { marriage scale. }\end{array}$ \\
\hline Anuar (2013) & $\begin{array}{l}\text { Female students expressed more positive attitudes toward } \\
\text { people with disabilities in various social contexts than the } \\
\text { male students. }\end{array}$ \\
\hline
\end{tabular}

Table 2: Studies on Attitudes towards People with Disabilities in the Social Context by Prior Contact with People with Disabilities Factor

\begin{tabular}{|c|l|}
\hline \multicolumn{1}{|c|}{ Study } & \multicolumn{1}{c|}{ Findings } \\
\hline Chen et al. (2002) & $\begin{array}{l}\text { American and Taiwanese college students who have contact } \\
\text { with people with disabilities were found to be more positive } \\
\text { than those who were not having the contact in terms of the } \\
\text { contact effect in the context of dating and marriage. }\end{array}$ \\
\hline
\end{tabular}




\begin{tabular}{|l|l|}
\hline $\begin{array}{l}\text { Brockelman, Olney } \\
\text { and Williams (2002) }\end{array}$ & $\begin{array}{l}\text { Undergraduate students who had personal experience or } \\
\text { a close personal relationship with people with disabilities } \\
\text { had significantly more favorable attitudes toward individu- } \\
\text { als with a variety of psychiatric disabilities than students } \\
\text { without such relationships. }\end{array}$ \\
\hline $\begin{array}{l}\text { Rojahn, Komelasky } \\
\text { and Man (2008) }\end{array}$ & $\begin{array}{l}\text { Rojahn et al. assessed the explicit ratings of romantic at- } \\
\text { traction of 44 undergraduate students toward their peers } \\
\text { with physical disabilities and found those students who } \\
\text { have family members with disability rated their peers with } \\
\text { disabilities as equally romantic as their peers without dis- } \\
\text { abilities. }\end{array}$ \\
\hline Hamdy et al. (2011) & $\begin{array}{l}\text { Egyptian and American college students who had expe- } \\
\text { rience with people with disabilities scored significantly } \\
\text { higher on the combined DSRGD Scale than students who } \\
\text { had never interacted with people with disabilities. }\end{array}$ \\
\hline Anuar (2013) & $\begin{array}{l}\text { Students who had prior contact with people with disabili- } \\
\text { ties were more likely to have more favorable attitudes in } \\
\text { the social domains. }\end{array}$ \\
\hline
\end{tabular}

Table 3 - Studies on Attitudes towards People with Disabilities in the Social Context by Citizenship (Cultural) Factor

\begin{tabular}{|l|l|}
\hline \multicolumn{1}{|c|}{ Study } & \multicolumn{1}{c|}{ Findings } \\
\hline Chen et al. (2002) & $\begin{array}{l}\text { American college students had significantly more positive } \\
\text { attitudes than did Asian students in the context of dating } \\
\text { and marriage. }\end{array}$ \\
\hline Hamdy et al. (2011) & $\begin{array}{l}\text { American students' perceptions were generally somewhat } \\
\text { more positive than the Egyptian students. In addition, } \\
\text { American students have more positive attitudes about peo- } \\
\text { ple with disabilities as co-workers and spouses. }\end{array}$ \\
\hline Anuar (2013) & $\begin{array}{l}\text { International students were found to have more favorable } \\
\text { attitudes than the American students in the context of dat- } \\
\text { ing, marriage, and work. }\end{array}$ \\
\hline
\end{tabular}

Table 4: Studies on Attitudes towards People with Disabilities in the Social Context by Disability Status Factor

\begin{tabular}{|l|l|}
\hline \multicolumn{1}{|c|}{ Study } & \multicolumn{1}{c|}{ Findings } \\
\hline Wong et al. (2004) & $\begin{array}{l}\text { The students' most preferred group was the adults with } \\
\text { physical disability and the least preferred group was those } \\
\text { with psychiatric disability. }\end{array}$ \\
\hline $\begin{array}{l}\text { Gordon, Chariboga- } \\
\text { Tantillo, Feldman, } \\
\text { and Perrone (2004) }\end{array}$ & $\begin{array}{l}\text { Students were least inclined to initiate friendships with or } \\
\text { marry people with mental retardation and psychiatric dis- } \\
\text { abilities even though 60\% expressed their willingness to } \\
\text { be friends with or marry those with physical disability and } \\
\text { sensory impairment. Mental retardation and psychiatric } \\
\text { disability were the least disability populations that being } \\
\text { rated by the undergraduate students when they were re- } \\
\text { quired to indicate their willingness to be friends with or } \\
\text { marry with persons with differing disabling conditions. }\end{array}$ \\
\hline
\end{tabular}


Rosenthal, Chan, \& Students had more preference for people with physical disLivneh (2006)

ability than those with schizophrenia and HIV/AIDS in the high stake scenario (i.e.; recruit and hire people with disabilities) and low stake scenario (i.e.; mentor or become a companion with people with disabilities). plex. In Hergenrather and Rhodes (2007) and Miller et al. (2009) studies, though women reported more positive attitudes in developing relationship as friend and coworker, they appeared to be more hesitant to initiate a serious relationship with persons with disabilities, such as, dating and marrying. Shakespeare and Tepper (1999) indicated that those females who chose to be involved in an intimate relationship felt more secure as they did not have to put emphases on sexual matters. Whereas Hamdy et al. (2011) study reported a contradicted outcome in which male students were more likely to have positive attitudes in the social context than were female students.

Various studies have reported significant impacts of having some level of relationships with people with disabilities on the individuals' attitudes toward this marginalized group. Tervo et al. (2004) and Chen et al. (2002) studies have reported that students with frequent contact with people with disabilities and those who had a relative with a disability would hold more favorable attitudes toward people with disabilities. As the scope of disability attitude study expands in the context of social situation, such as, work, friendship, and marriage, researchers have also found the link of the extent of contact with people with disabilities with the individuals' attitudes in developing relationship as co-worker, friend, and partner or spouse. Chen et al. (2002) and Hamdy et al. (2011) studies have reported more favorable attitudes among college students who have contact with people with disabilities in the context of dating, marriage and work.

There have not been many exten- sive research works on associating disability attitude with the cultural status. Several comparison studies have been conducted to assess the differences of attitudes between American students or faculty and students or faculty from other part of countries, i.e., American and Egyptian students, American and Israeli faculty, American and Jordanian faculty, and American, Taiwanese and Singaporean, American and Egyptian students). Regardless of whether the focus of the disability attitude study is in general or in a more specific social situation, all researchers have reported more favorable attitudes among American participants compared with participants from other countries. These differences were explained by few factors, such as, degree of westernization, cultural values, and law and regulations. In contrast, Anuar (2013) indicated that the international students have more favorable attitudes towards people with disabilities in the social context. There was only a study that assessed the influence of racial background factor (African American, Asian American, Latin American, and European American) on the college students' attitudes toward people with disabilities by Saetermoe, Scattone, and Kim (2001). They indicated that Asian American had more tendency to hold unfavorable attitudes toward people with physical disabilities and cognitive disabilities than were the European American, Latin American, and African American students.

Little is known about the literatures that are associated with the disability status of the observers but instead, there were some studies made on the perceptions toward people with specific types of disabilities. Wang, Thomas, Chan, and Cheing (2003) have only ranked the students' disability preference in their study 
and they did not study on whether one with disability or without disability would have a positive or negative perception towards people with disabilities. Whereas, Deal (2003) indicated that disability categorization is utilized by individuals with disabilities to determine their attitudes toward people with disabilities similarly with the individuals without disabilities. According to Deal, persons with disabilities individualize their perceptions and they view other persons with disabilities as different from them as an individual. The disability preference of the students has also become a focus in assessing attitudes toward people with disabilities in the social context and the researchers have identified a pattern in the way the participants were making decisions on their disability preference and they found that the least stigmatized disability group was those with physical disabilities and the most stigmatized disability group was those with psychiatric, and cognitive disabilities (Gordon et al., 2004; Rosenthal et al., 2006; Wong et al., 2004). Some of the research findings have inferred that an individual's willingness to develop relationship at certain social level with a person with disability was influenced by their knowledge about the severity or stability of the person's disability. Gordon et al. (2004) reported students rated the least on groups with mental retardation and psychiatric disabilities when they were asked about their willingness to be friends with or marry with persons with differing disabling conditions while in the Miller et al. (2009) study, the students were more likely to become reluctant to date or marry with a person who have a more severe type of disability.

\section{CONCLUSION}

Given the persistence of negative attitudes toward people with disabilities, there is a need to create a positive environment and it requires assessments of existing individuals' attitudes about people with disabili- ties. In addition, it is essential to explore attitudes toward people with disabilities in a more specific dimension. It would also be very beneficial to design programs at the college level for increasing education and awareness about disabilities among college students. The training should not only be a knowledge-based type of training, but also a practice-based training where students can apply their knowledge about disability and interact with other students with disabilities to bridge the gaps between these groups. Realistically, attitudes toward disability should be measured on the basis of social context and specific disability (Grand et al., 1982). When the attitudes toward people with disabilities are measured in a situational context, the outcome will provide a meaningful and practical interpretation on exploring individuals' attitudes toward people with disabilities.

\section{REFERENCES}

Anuar, A. (2013). Attitudes of college students toward people with disabilities in various social contexts (Doctoral dissertation). (UMI No. 3587952).

Antonak, R. F. (1981). Prediction of attitudes towards disabled persons: a multivariate analysis. Journal General Psychology, 789-884.

Asch, A., \& Fine, M. (1988). Introduction: Beyond pedestais. In M. Fine, \& A. Asch (Eds.), Women with disabilities: Essays in psychology, culture, and politics. Philadelphia, PA: Temple University Press.

Brockelman, K. F., Olney, M. F., \& Williams, S. S. (2002). Social distance in response to psychiatric labels. International Journal of Rehabilitation Research, 25, 253-259.

Chen, R. K., Brodwin, M. G., Cardosa, E., \& Chan, F. (2002). Attitudes toward people with disabilities in the 
social context of dating and marriage: A comparison of American, Taiwanese, and Singaporean college students. Journal of Rehabilitation, 68(4), 5-11.

Deal, M. (2003). Disabled people's attitudes toward other impairment groups: A hierarchy of impairments. Disability and Society, 18(7), 897-910.

DeLoach, C. (1994). Attitudes toward disability: Impact on sexual development and forging of intimate relationships. Journal of Applied Rehabilitation Counseling, 25, 18-25.

Fitcten, C. S., Robillard, K., Judd, D., \& Amsel, R. (1989). College students with a physical disability: Myths and realities. Rehabilitation Psychology, 34(4), 243-257.

Fitcten, C. S., Goodrick, G., Amsel, R., \& McKenzie, S. W. (1991). Reactions toward dating peers with visual impairments. Rehabilitation Psychology, 36(3), 163-178.

Gill, C. J. (1996). Dating and relationship issues. Sexuality and Disability, 14, 183-191.

Goldstein, S. B., \& Johnson, V. A. (1997). Stigma by association: Perceptions of the dating partners of college students with physical disabilities. Basic and Applied Social Psychology, 19(4), 495-504.

Gordon, P. A., Chariboga-Tantillo, J., Feldman, D., \& Perrone, K. (2004). Attitudes regarding interpersonal relationships with mental illness and mental retardation. Journal of Rehabilitation, 70(1), 50-56.

Gordon, E. D., Minnes, P. M., \& Holden, R. R. (1990). The structure of attitudes toward persons with a disability, when specific disability and context are considered. Rehabilitation Psychology, 35, 87-89.
Grand, S. A., Bernier, J. E., \& Strohmer, D. C. (1982). Attitudes toward disabled persons as a function of social context and specific disability. Rehabilitation Psychology, 27(3), 165-173.

Hamdy, N. N., Auter, P. J., Humphrey, V. F., \& Attia, A. (2011). A cultural perspective: A survey of U.S. and Egyptian students regarding their perceptions of people with 90 disabilities. International Journal of Humanities and Social Science, 1 (5), 83-93.

Hergenrather, K., \& Rhodes, S. (2007). Exploring undergraduate student attitudes toward persons with disabilities: application of the disability social relationship scale. Rehabilitation Counseling Bulletin, 50(2), 66-75.

Karnilowicz, W., Sparrow, W., \& Shinkfield, A. (1994). High school students' attitudes toward performing social behaviors with mentally retarded and physically disabled peers. Journal of Social Behavior and Personality, 9, 65-80.

Miller, E., Chen, R., Glover-Graf, N.M., \& Kranz, P. (2009). Willingness to engage in personal relationships with persons with disabilities: Examining category and severity of disability. Rehabilitation Counseling Bulletin, 52, 211-224.

Olkin, R. (1999). What psychotherapists should know about disability. New York: Guilford Press.

Rojahn, J., Komelasky, K. G., \& Man, M. (2008). Implicit attitudes and explicit ratings of romantic attraction of college students toward opposite sex peers with physical disabilities. Journal of Developmental and Physical Disability, 20, 389-397.

Rosenthal, D. A., Chan, F., \& Livneh, H. (2006). Rehabilitation students' at- 
titudes toward persons with disabilities in high and low stakes social contexts: A conjoint analysis. Disability and Rehabilitation, 28(24), 1517-1527.

Rubin, S. E., \& Roessler, R. (2008). Foundations of the vocational rehabilitation process (6th ed.). Austin, TX: PRO-ED.

Saetermoe, C. L., Scattone, D., \& Kim, K. H. (2001). Ethnicity and the stigma of disabilities. Psychology and Health, 16(6), 699-713.

Shakespeare, T. W. (1999). Losing the plot? Discourses on genetics and disability. Sociology of Health and Illness, 21(5), 669-688.

Siller, J. (1964). Personality detriments: A reaction to the physically disabled. American Foundation Research Bulletin, 66(7), 37-52.

Stovall, C., \& Sedlacek, W. (1983). Attitudes of male and female university students toward students with different physical disabilities. College Student Personnel, 26, 325-330.

Strohmer, D. C., Grand, S. A., \& Purcell, M. J. (1984). Attitudes toward persons with a disability: An examination of demographic factors, social context, and specific disability. Rehabilitation Psychology, 29(3), 131-145.

Tepper, M. S. (1999). Letting go of restrictive notions of manhood: Male sexuality, disability and chronic illness. Sexuality and Disability, 17(1), 37-52.

Tervo, R. C., Palmer, G., \& Redinius, P. (2004). Health professional student attitudes towards people with disability. Clinical Rehabilitation, 18, 908-915.

Wahl, O., \& Aroesty-Cohen, E. (2010). Attitudes of mental health professionals about mental illness: A review of the recent literature. Journal of
Community Psychology, 38(1), 4962.

Wang, M.-H., Thomas, K.R., Chan, F., \& Cheing, G. (2003). A conjoint analysis of factors influencing American and Taiwanese college students' preferences for people with disabilities. Rehabilitation Psychology, 48(3), 195-201.

Wong, D., Chan, F., Cardoso, E., Lam, C., Miller, S. (2004). Rehabilitation counseling students' attitudes toward people with disabilities in three social contexts: A conjoint analysis. Rehabilitation Counseling Bulletin, 47(4), 194-204. 